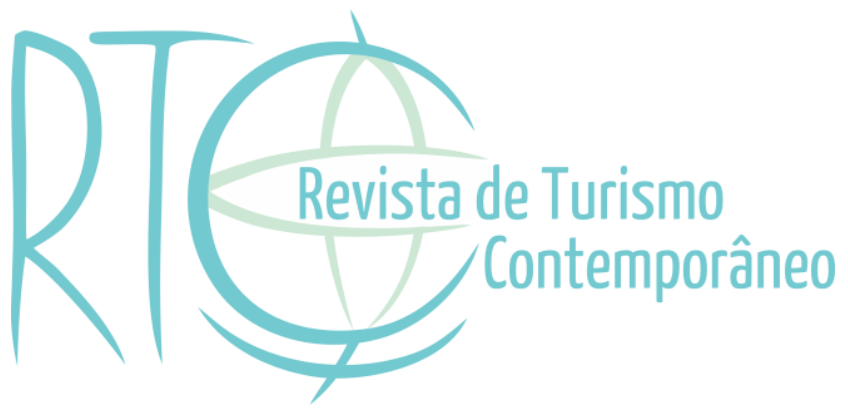

\title{
Afroempreendedorismo no turismo, desigualdade racial e fortalecimento da identidade negra
}

\section{Afro-entrepreneurship in tourism, racial inequality and strengthening of black identity}

Natália Araújo de Oliveira

Doutora em Sociologia pela Universidade Federal do Rio Grande do Sul - UFRGS, Porto Alegre/RS, Brasil

E-mail: oliveira.natalia@outlook.com

Artigo recebido em: $27-08-2020$

Artigo aprovado em: 19-10-2020 


\section{RESUMO}

O afroempreendedor é o empreendedor negro que busca, por meio do seu trabalho, valorizar a cultura negra e fazer dela seu meio de renda e apoio. No turismo, o afroempreendedorismo é realizado por meio do afroturismo, que é pautado por experiências afroreferenciadas na atividade. A presente pesquisa tem por objetivo discutir como o afroempreendedorismo em turismo pode contribuir para a redução da desigualdade racial e para o fortalecimento da identidade negra no Brasil. Para tanto, uma pesquisa, de cunho qualitativo, foi realizada junto a quinze afroempreendedores da área no país, que responderam um questionário enviado via Google Forms. A técnica de amostragem não probabilística usada foi a bola de neve, na qual os entrevistados indicavam outras pessoas para também responderem à pesquisa. Os afroempreendedores pesquisados eram pretos, em sua maioria mulheres, com alta escolaridade, que trabalhavam principalmente com agenciamento e guia. A pesquisa mostrou que o afroempreendedorismo no turismo auxilia na redução da desigualdade racial e na afirmação da identidade negra de sete diferentes maneiras, a saber: no resgate da memória do povo preto por meio de narrativas turísticas; na valorização das narrativas negras e da ancestralidade; na formação de empreendedores negros que valorizam sua ancestralidade; na construção de medidas antirracistas nos modelos de negócios; na mudança da visão do negro como mão de obra; na educação de jovens e no aumento da renda e inclusão de capital de giro para a população afrodescendente.

Palavras-chave: Afroempreendedorismo. Turismo. Redução da Desigualdade Racial. Fortalecimento da Identidade Negra.

\section{ABSTRACT}

The afro-entrepreneur is the black entrepreneur who seeks, through his work, to value black culture and make it his means of income and support. In tourism, afro-entrepreneurship is carried out through afroturism, which is based on afroreferenced experiences in the activity. This research aims to discuss how afro-entrepreneurship in tourism can contribute to the reduction of racial inequality and the strengthening of black identity in Brazil. To this end, a qualitative survey was carried out with fifteen afro-entrepreneurs in the area in the country, who answered a questionnaire sent via Google Forms. The non-probabilistic sampling technique used was the snowball, in which interviewees indicated other people to also answer the survey. The afro-entrepreneurs surveyed were black, mostly women, with high schooling, who worked mainly with agency and guide. The research showed that afro-entrepreneurship in tourism helps to reduce racial inequality and affirm black identity in seven different ways, namely: in the rescue of the memory of black people through tourist narratives; valuing black narratives and ancestry; in the formation of black entrepreneurs who value their ancestry; in the construction of anti-racist measures in business models; in changing the view of blacks as labor; in youth education and in increasing income and inclusion of working capital for the Afro-descendant population.

Keywords: Afro-Entrepreneurship. Tourism. Reduction of Racial Inequality. Strengthening of Black Identity. 


\section{INTRODUÇÃO}

O negro no turismo é um tema pouco estudado na academia. Dos trabalhos que abordam a temática, há poucas ou mesmo nenhuma análise acerca do negro que empreende no turismo, em especial aquele que busca, por meio do turismo, fortalecer a identidade e a cultura negra por meio de narrativas afrocentradas, sendo este o conceito adotado nesta pesquisa - do afroempreendedor como aquele empreendedor negro que volta seu trabalho para a valorização da cultura afro.

A despeito do assunto não ser ainda recorrente em ambientes universitários, o afroempreender em turismo tem ganhado cada vez mais notoriedade na mídia (Moherdaui, Datt, \& Moura, 2019) e há uma procura maior por roteiros de turismo voltados ao afroturismo (ou ainda turismo étnico afro), ainda que haja afroempreendedores que já estão neste circuito há mais de dez anos.

Ao basear seu empreendimento em narrativas afroreferenciadas, os afroempreendedores buscam gerar renda entre os negros, auxiliando na luta contra a desigualdade social, tão patente no Brasil e que aflige de maneira muito mais intensa os negros, haja vista que, embora sejam maioria no país $(55,8 \%$ da população) (Instituto Brasileiro de Geografia e Estatística - IBGE, 2019), eles os tem piores salários (Equipe Lupa, 2018) e possuem taxas de analfabetismo mais altas (IBGE, 2018). Deste modo, por este caminho, o afroempreendedorismo auxilia na busca por uma sociedade mais igualitária.

Outra frente em que o afroempreendedorismo atua é na luta contra o racismo e na valorização da identidade negra e a maneira pela qual ele age, nesta vertente, será vista neste artigo, que tem como objetivo discutir como o afroempreendedorismo em turismo pode contribuir para a redução da desigualdade racial e para o fortalecimento da identidade negra no Brasil. Para auxiliar neste debate, 15 afroempreendedores em turismo responderam uma pesquisa, enviada via Google Forms. As respostas por ele pensadas foram categorizadas e aqui discutidas.

O trabalho está dividido em cinco partes e, após a introdução, o referencial teórico, que discute o afroempreendedorismo, é apresentado. Em seguida, as bases metodológicas são delineadas para, posteriormente, terem seus resultados expostos e discutidos no próximo tópico. Na conclusão há um apanhado geral acrescido de reflexões sobre o que foi encontrado. 


\section{REFERENCIAL TEÓRICO}

Afroempreendedorismo e empreendedorismo negro são temas importantes quando se discute o empreender no turismo e, embora os termos pareçam sinônimos, apresentam uma diferença importante, em especial quando voltado para a área aqui estudada - o turismo, que conta histórias e reforça ou mesmo apaga narrativas.

Neste sentido, partirei do mais amplo para o mais específico, ainda que não haja consenso entre intelectuais e ativistas da área. Por exemplo, enquanto as pesquisas do Serviço Brasileiro de Apoio às Micro e Pequenas Empresas (Sebrae) e do Global Entrepreneurship Monitor (GEM), além de vários coletivos de empreendedores negros e mesmo produções intelectuais (Nogueira, 2013), afirmam que empreendedorismo negro e afroempreendedorismo são sinônimos, usando inclusive outros termos para fazer referência à temática, como empreendedor afro-brasileiro, ativistas e autores (Nascimento, 2017; Nascimento, 2018) apontam uma diferença importante entre ambos, algo que o Pretahub (2019) vai chamar de engajamento. Assim, o afroempreendedorismo será visto aqui como o empreender do negro que busca, por meio do seu trabalho, valorizar a cultura negra por meio de um comércio que dá visibilidade a esta e que nela se apoia. Em termos mais claros, os afroempreendedores se diferenciam dos empreendedores autodeclarados negros por representarem um segmento que une o ativismo social contra o racismo por meio das relações de consumo (Nascimento, 2017).

No segmento do turismo, falar em afroempreender é discutir a construção de um turismo empreendido por negros que se baseia na construção de narrativas afrocentradas, ou ainda de hospedagens, experiências e vivências que permeiam a cultura negra.

O afroempreendedorismo e mesmo o empreendedorismo negro é um tema pouco estudado na academia, seja em turismo, em ciências sociais ou mesmo em administração, sendo considerado um tema marginal (Oliveira, Pereira, \& Souza, 2013) e tem ganhado destaque apenas nos últimos anos (Oliveira, 2019). No turismo, os estudos que citam afroempreendedores tem como foco a pauta racismo, imbuída na motivação para abertura de uma empresa da área (Domingos, Pimentel, \& Queiroz, 2018), tema relevante para compreender o surgimento do setor.

Pensar no afroempreendedorismo é discutir como o empreender da e para a cultura negra envolve uma rede que busca se fortalecer por meio de seus negócios, em um ecossistema de produção de negros para negros. A ideia desta cadeia é chamada de Black Money. 
Silva (2019) explica que o movimento Black Money, também denominado de Dinheiro Preto, já existe há muito tempo nos Estados Unidos e envolve uma cadeia em diferentes pontas de produção. Ele conta que o movimento surgiu como filosofia pregada por Marcus Garvey, jamaicano e ativista do movimento nacionalista negro, que considerava essa ação importante para "fazer com que as comunidades negras investissem nelas mesmas, gerando riqueza social e intelectual".

Em termos próximos ao do intelectual jamaicano, Silva (2019) define Black Money como o "incentivo do consumo de produtos e serviços produzidos por negros, e o ato de fazer o dinheiro circular entre a comunidade afrodescendente por mais tempo, gerando consciência social, econômica e financeira". A proposta do Black Money envolve o fortalecimento da comunidade negra, gerando renda, trabalho e também empoderamento, todas as proposições presentes quando se fala em afroempreendedores. Como Nascimento (2018, p. 2) afirma, os afroempreendedores, em sua maioria:

afirmam a luta contra o racismo, promovem a visibilidade positiva da identidade negra, realizam atividades voltadas para o empoderamento estético e identitário da população afro-brasileira. Para isso, eles fomentam o afroempreendedorismo e o afroconsumo como estratégia de enfrentamento à vulnerabilidade econômica e social.

Esta rede de afroempreendedorismo, que tem como foco nesta pesquisa o turismo no Brasil, começa a se organizar. Em 2019 foi realizado, no Brasil, o I e II Fórum de Afroturismo e, no mês de junho de 2020 foi realizado um cadastro para mapeamento do setor. (Dias, 2020a), que tem por objetivo, de acordo com Dias (2020b): "monitorar o setor para potencializar suas ações, gerar oportunidades e políticas públicas”.

O mapeamento do afroturismo no Brasil permitirá conhecer, de maneira mais ampla, os afroempreendedores em turismo do país (ainda que, para empreender em afroturismo, ser negro não seja uma condição sine qua non). Sabendo quem são essas pessoas, quantas são, onde atuam, será mais fácil traçar, de maneira mais fidedigna, seus perfis e perceber como veem o setor e quais dificuldades ele traz. Para contribuir neste sentido, o presente trabalho traz a perspectiva de 15 afroempreendedores em turismo do país, analisando, em especial, suas opiniões acerca de como o afroempreendedorismo pode contribuir para a redução da desigualdade racial e para a afirmação da identidade negra no Brasil. 


\section{METODOLOGIA}

A pesquisa é cunho qualitativo, caracterizada como descritiva, que é costumeiramente mais usada em pesquisas em turismo, na qual há uma descrição sistemática, objetiva e precisa das características de uma determinada população ou área de interesse (Schlüter, 2003).

O universo da pesquisa foi composto por afroempreendedores em turismo do Brasil e, com o intuito de encontrar estas pessoas, diferentes fontes foram usadas, sendo amostragem utilizada a "bola de neve", que é uma técnica não probabilística usada em pesquisas sociais onde os participantes iniciais de um estudo indicam novos participantes. Estes, por sua vez, indicam outros participantes e assim sucessivamente, utilizando cadeias de referências, redes de contato (Baldin \& Munhoz, 2011).

As primeiras fontes para encontrar essas pessoas foram militantes de movimentos negros, associações voltadas ao empreendedorismo negro, coletivos de viagem afrocentrados e o site Guia Negro, um portal de conteúdo sobre cultura negra e turismo étnico afro, que existe desde 2017 e que publicou, no começo de 2020, uma notícia cujo título era: “O ano do afroturismo no Brasil: novas empresas, novas viagens, fóruns e redes" (Dias, 2020a), que continha nome de algumas empresas de turismo afroncentadas do país.

Após o conhecimento inicial dos empreendedores do ramo, entrei em contato (via email, WhatsApp, Facebook) e solicitei que respondessem o questionário, que foi formulado via Google Forms, cujo link era enviado. Também era solicitado que os respondentes o repassassem aos contatos da área que se encaixassem no perfil procurado. É válido salientar que foi realizado um pré-teste antes do envio do questionário. O questionário tinha 28 perguntas, sendo 25 fechadas e 03 abertas e, nas fechadas, havia opções dicotômicas e também de múltipla escolha. O questionário ficou disponível na internet entre os dias 16 a 26 de junho de 2020. Comentarei neste artigo os resultados de uma das perguntas abertas, que era: "Como o afroempreendedorismo pode contribuir para a redução da desigualdade racial e para a afirmação da identidade negra no Brasil?”".

O questionário foi respondido por 15 afroempreendedores e as respostas, referentes à pergunta na qual orbita o presente trabalho, foram posteriormente categorizadas de maneira a aglutinar as ideias, sendo apresentadas no próximo tópico. 


\section{ANÁLISE E DISCUSSÃO DOS RESULTADOS}

Antes destrinchar as falas dos pesquisados serão apresentadas informações básicas sobre o perfil destes e de suas empresas, a fim facilitar a compreensão do lugar de onde eles falam. O grupo de respondentes da pesquisa foi composto por 12 mulheres e 03 homens, todos se autodeclaram como pretos, sendo a faixa etária da maioria de 30 a 39 anos (8). Os demais possuem de 18 a 39 anos (4) e de 40 a 59 anos (3). Apenas um deles estudou até o ensino médio, os demais ou estão cursando graduação (1) ou já são graduados (8) e pósgraduados (5). A maioria trabalha com agenciamento e guia, são microempreendedores (8 pessoas), possuem microempresa (5), empresa de pequeno porte (1) ou sequer são formalizados (1). Todos afirmam saber o que é Black Money e afirmam dar preferência a outros afroempreendedores quando utilizam serviços ou fazem compras.

A pergunta em torno da qual esse trabalho se foca é a discussão sobre como o afroempreendedorismo em turismo pode contribuir para a redução da desigualdade racial e para a afirmação da identidade negra no Brasil. Esse questionamento, respondido de maneira livre pelo pesquisados, trouxe várias pontos de reflexão sobre os quais me debruçarei ao longo das próximas páginas. Não me focarei aqui em fazer uma contagem de recorrência acerca do que foi dito por cada um dos entrevistados, meu objetivo é ver, da maneira mais ampla, os pontos de convergência assumidos pelos que trabalham na área.

As respostas acerca da pergunta que norteia o artigo orbitaram em torno de sete categorias, criadas a partir das respostas listadas, a saber: resgate da memória do povo preto por meio de narrativas turísticas; valorização das narrativas negras e de sua ancestralidade; renda e inclusão de capital de giro para a população afrodescendente; construção de medidas antirracistas nos modelos de negócios; formação de empreendedores negros que valorizam sua ancestralidade; mudança da visão do negro como mão de obra e educação de jovens.

Ainda que pareça haver uma sobreposição entre as categorias resgate da memória do povo preto por meio de narrativas turísticas e valorização das narrativas negras e de sua ancestralidade, parto de uma separação que discute como as memórias subterrâneas (Pollak, 1989) passam a emergir no turismo e cobrar seu lugar quando se pensa no resgate da memória. Já ao discutir a valorização das narrativas negras, penso em roteiros já estabelecidos, mas que não são reconhecidos em sua importância.

Como afirma Munanga (1999, p. 50), os pensadores do Brasil do final do século XIX, ao buscarem explicar a situação racial do país a partir dos intelectuais europeus - tidos como desenvolvidos, assinalaram a mestiçagem como uma maneira de "[...] estragar e degradar a 
boa raça" ou ainda como "[...] um meio para reconduzir a espécie a seus traços originais". Como resultado, na intenção de se padronizar a identidade nacional, as identidades indígenas e afrodescendentes do país foram cada vez mais desvalorizadas, isso quando não foram criminalizadas ou taxadas de loucura, como explica Silva (2008) ao fazer referências às religiões de matriz africana. Logo, se percebe por que a memória deste grupo é aqui analisada como uma memória subterrânea.

A discussão sobre memória subterrânea vem de Pollak (1989). O autor discute o tema quando explica que existem memórias oficiais e subterrâneas, sendo a segunda a memória dos grupos marginalizados, das minorias, dos excluídos. Aos marginalizados é relegado o esquecimento, o apagamento da sua história, contudo, é uma memória em constante movimento.

Vale lembrar que a categorização não é estanque, isto é, assim como a identidade é mutável, a memória, também pode sofrer alterações com o passar do tempo. É essa alteração que se pede no turismo e por essa mudança que os afroempreendedores aqui ouvidos trabalham todos os dias, para que a memória do seu povo seja resgatada e contemplada em sua potência. Como afirmou um dos respondentes da pesquisa, o afroempreendedorismo pode contribuir com o "resgate da memória do povo preto através de ações turísticas" ou ainda, como outro disse: "na formação da cultura e no recontar da história dos povos negros".

Souza (2012, p. 3) explica que a história dos afrodescendentes no Brasil por muito tempo foi descrita de maneira incompleta, isto é, a única referência era ser descendente de escravizados, como se a história das populações africanas vindas para o Brasil tivesse tido início com a escravidão. A autora explica que a identidade e a memória da sociedade brasileira negra foram estabelecidas neste contexto, sem especificação de descendência, isso quando não houve tentativas de branqueamento da população do país, fomentadas por pensadores e cientista nos séculos XIX e início do XX. Ademais, segue a autora, a complexidade no cenário em que se deu a constituição da identidade afrodescendente no Brasil estará presente na literatura, na educação etc., de maneira a esvaziar "toda uma população de historicidade e memórias de si, haja vista que até mesmo os processos de resistências são minimizados e/ou negligenciados dentro das literaturas históricas".

É neste contexto que os afroempreendedores buscam a resgate da história do seu povo, não somente na sociedade como um todo, mas também no turismo, de modo que suas memórias emerjam e se tornem espaços de reconhecimento, de luta, de resistência, de fé, de trabalho, de lazer. No turismo, falar de resgate da memória do povo preto por meio de 
narrativas turísticas afrocentradas é apontar os silêncios do turismo, visto que essas memórias são apagadas pelo discurso preponderante. Neste sentido, analisar o turismo como um fenômeno social que é, exige dar atenção às relações de poder e dominação que resultam dos discursos hegemônicos da atividade, como afirmam Mowforth e Munt (como citado em Fazito, 2015).

A ideia é construir um turismo crítico, que perceba como ele também está imbuído em um discurso eurocêntrico que valoriza apenas o branco e sua história colonizadora. Como comenta Fazito (2015, p. 122), no turismo crítico a ideia é "dar voz a pessoas e comunidades, a populações [...] oprimidas pelos processos derivados dos programas de desenvolvimento turístico que seguem os discursos dominantes de desenvolvimento". Nas pesquisa em turismo, os discursos pós-colonialistas agregam ao fugir de óticas eurocêntricas e focar na valorização de outras histórias, abrindo novos caminhos que levam o turista a redimensionar sua própria história, com um olhar interpretativo dos lugares, fugindo da lógica modernizante que o turismo convencional costuma impor.

Na perspectiva acima descrita, o turismo auxilia no resgate de memórias dos povos pretos, sedimentando-os em lugares de memória (Nora, 1993), que serão visitados e narrados por meio de sua própria história. Este sentimento de pertencimento é um constitutivo da identidade, vista a partir da lógica do contraste com o outro. Além disso, é importante lembrar que as identidades são múltiplas, inacabadas e instáveis, sejam elas individuais ou coletivas, como esclarece Agier (2001).

A identidade é construída a partir da matéria-prima fornecida pela história, geografia, biologia, instituições produtivas e reprodutivas, assim como pela memória coletiva, pelos aparatos do poder, entre outros aspectos. (Castells, 2000). Logo, todas as pautas que compõem a identidade são processadas pelos indivíduos, pelos grupos sociais e sociedades, que reorganizam seus significados a partir de seus projetos culturais, envolvidos em sua estrutura social, assim como na visão de tempo e de espaço de um dado grupo (Oliveira, 2010).

A ideia dos afroempreendedores é que o turismo seja um vetor de resgate da memória dos negros e, consequentemente, fortalecimento da identidade. Assim, estes espaços, quando formatados para o turismo, precisam se tornar conhecidos a fim de atrair visitantes. Contudo, mais que transformar estes espaços em atrativos turísticos, é necessário dar a ele a profundidade que merece ter. Eles contam uma história e muitos se reconhecem nela, como será visto. 
A valorização aqui destacada não parte apenas do reconhecimento daquele espaço como um atrativo interessante, ou ainda um item daqueles "não posso sair dessa cidade sem ter ido naquele lugar". O objetivo é mais amplo e envolve a identificação do turista com aquela narrativa, que sente que sua história e de seu povo é contada naquele espaço. Vale destacar que esta história não precisa estar ligada apenas a um passado de sofrimento e escravização, ainda que estes também sejam importantes para a construção da identidade negra, mas que também dê atenção aos demais itens formadores de uma identidade, como a fé, o trabalho, as festas, o lazer, a militância e tantos outros.

Souza (2012, p. 1) explica que:

\begin{abstract}
Quando pensamos na afrodescendência como fator articulador da memória e identidade negra estejamos atentos que os lugares de memória não são apenas material, mas também simbólicos e funcional. Como sujeitos históricos, buscamos nosso lugar de identificação com o passado e presente no tempo e no espaço quer seja físico ou imaginário, porém a memória é um processo indissociável da trajetória de vida dos seres humanos.
\end{abstract}

Neste sentido, pensar na identidade em espaços de turismo construídos em narrativas afroreferenciadas é discutir o reconhecimento de uma identidade, lembrando que esta é criada na interação com o outro. Assim, o mote dos pesquisados é de que afroturismo contribui para a valorização das narrativas e da identidade negra, pois o viajante negro vê aqueles lugares de memória, nos quais a sua ancestralidade é reconhecida e vista como algo a ser celebrado, e se sente pertencer àquele espaço, se reconhece nele e valoriza sua própria identidade.

Como um dos respondentes da pesquisa explicou, o afroempreendedorismo negro no turismo auxilia na valorização da identidade negra ao construir “(...) narrativas afrocentradas, principalmente no ramo do turismo. Fazer com que as pessoas revisitem a história de um ponto de vista afroreferenciado e não mais dirigente é de extrema importância na construção dessa afirmação". Também neste caminho, outro participante afirma que "as vivências propostas pelo afroturismo reverberam na pessoa por muito tempo e de maneiras muito particulares que vão além do que podemos imaginar quando criamos os roteiros, então é uma virada de chave para muitos".

Outra categoria estabelecida pelos respondentes e que caminha muito próxima às duas anteriores, mas que precisa ter sua autonomia quando pensada em sua relevância é a ideia que o afroempreendedorismo auxilia na formação de empreendedores negros que valorizam a sua ancestralidade. Souza (2012) lembra que por muito tempo muitas pessoas rejeitavam sua afrodescendência, o que, conforme a autora, deve ser analisado com bastante cuidado a fim de não estabelecer uma relação simplista de negação da identidade. Por um longo período houve 
pouco espaço de afirmação e reconhecimento das identidades negras e os grupos os faziam, ao longo dos séculos XVII à XX, foram violentamente desarticulados, de maneira que a violência foi utilizada para coibir e intimidar tudo que remetesse à memória africana. Embora a resistência nunca tenha deixado de existir, foi criminalizada. (Souza, 2012). Além disso, a associação do negro com coisa "ruim", "errada", "feia", "pecaminosa", "criminosa" e muitos outros artifícios racistas usados ao longo da história do país serviram para minar essa autoidentificação.

Uma discussão sobre miscigenação racial e o mito da democracia racial do país são importantes para se pensar nessa resistência à identidade negra. Ainda que não seja possível aqui aprofundá-la, é necessário entender como ela contribuiu e ainda contribui - ainda que cada vez mais pessoas se reconheçam como pretas -, para que as pessoas não se reconheçam como negras. Deixarei Carneiro (2009) nos guiar na explicação.

De acordo com a autora, a miscigenação deu e dá suporte ao mito da democracia racial na medida em que o intercurso sexual entre brancos, indígenas e negros seria um indicativo de nossa tolerância racial. Todavia, este argumento omite o estupro colonial praticado pelo colonizador sobre mulheres negras e indígenas. A miscigenação tem sido um instrumento eficaz de embranquecimento do país, estabelecendo uma hierarquia cromática e de fenótipos que têm na base o negro retinto e no topo o branco. Aos intermediários é dado o benefício simbólico de estarem mais próximos do ideal humano, o branco.

Ainda segundo Carneiro (2009), essa hierarquização impacta particularmente os negros brasileiros, pois esse imaginário social, que indica uma suposta melhor aceitação social dos mais claros em relação aos mais escuros, faz com que as pessoas negras ou seus descendentes miscigenados adotem, para se definirem racialmente, termos como: moreno escuro, moreno claro, moreno-jambo, marrom-bombom, mulato, mestiço, caboclo, mameluco, cafuzo, isto é, temos confusos que são agregados na categoria social pardos, do Instituto Brasileiro de Geografia e Estatística (IBGE), o que ninguém consegue definir como raça ou cor. Como esclarece a autora:

Talvez o termo pardo se preste apenas para agregar os que, por terem a sua identidade étnica e racial destroçada pelo racismo, pela discriminação e pelo ônus simbólico que a negritude contém socialmente, não sabem mais o que são ou simplesmente não desejam ser o que são.

Cada vez mais as pessoas se reconhecem como pretas. De acordo com a Pesquisa Nacional por Amostra de Domicílios (Pnad) de 2018, o índice passou de 7,4\% em 2012 para 9,3\% em 2018. (Barbosa, 2019). É nesta categoria que os afroempreendedores aqui estudados 
se incluem, como pretos. O número de pardos também tem crescido e, em 2007, pela primeira vez, o percentual de negros (pretos e pardos) superou o de brancos no Brasil e estes índices crescem a cada ano, segundo a Pnad de 2014. (Rossi, 2015). Para Katia Regis, coordenadora da primeira licenciatura do Brasil de estudos africanos e afro-brasileiros, o crescimento da população que se autodeclara negra é reflexo de anos de luta do movimento negro e também do acesso à educação. Em suas palavras: "A população negra que tem mais acesso ao conhecimento efetivo da história africana e afro-brasileira passa a se ver mais positivamente como negra" (Rossi, 2015).

Logo, o fato de se ter mais negros que reconhecem sua ancestralidade também é refletida no empreendedorismo e o turismo auxilia, segundo os entrevistados, neste movimento, em especial no afroempreender. Como afirmou um dos entrevistados:

\section{A contribuição [do afroempreender em turismo para redução da desigualdade racial e para a afirmação da identidade negra] se dá a partir da [...] da formação de empreendedores negros que buscarão cada vez mais valorizar sua ancestralidade. (grifo meu).}

Outro ponto salientado pelos empresários pesquisados foi a ideia de que o afroempreender em turismo auxilia na mudança da visão do negro como mão de obra. Hintze e Almeida Júnior (2012) fizeram uma análise da revista Viagem e Turismo, da editora Abril, referentes às edições dos anos 2009 (159-165), 2010 (171-176) e 2011 (183-188) com o intuito de perceber as representações dos papéis de brancos e negros daquela publicação. Os resultados da pesquisa são muito pertinentes ao estudo aqui analisado pois mostram como os negros são retratados no turismo.

Na pesquisa de Hintze e Almeida Júnior (2012) foram analisadas imagens das seções: "Viajantes"; "Gente"; a equipe de colaboradores da revista, além de imagens de publicidade. Na publicidade, nas imagens de casais, $97,50 \%$ das imagens eram de pessoas brancas e 2,50\% negras; nas fotos de casais com crianças, $100 \%$ eram de pessoas brancas; nas fotos de um dos pais com criança, 94,44\% eram brancos e 5,56\% negros e, quando havia somente crianças, $95,24 \%$ eram brancas e $4,76 \%$ negras. As publicidades de grupo de amigos foi a mais que teve negros, com 11,43\%. (Hintze \& Almeida Júnior, 2012).

A seção "Viajantes" mostrava imagens de leitores e era subdividia em "Eu fui", em que não havia nenhum negro, “Acabei de chegar”, na qual 99,48\% das imagens eram turistas brancos contra $0,52 \%$ de negros e "Colecionadores de viagens", com apenas um negro, representando 6,25\%, contra 93,75\% de brancos. (Hintze \& Almeida Júnior, 2012). Nas 
imagens da "equipe da revista", na qual são apresentados os responsáveis pela edição e colaboradores, não havia negros. (Hintze \& Almeida Júnior, 2012).

Os autores salientam, a partir da pesquisa realizada, que a cor dos turistas é sempre branca. Como hipótese, afirmam que:

\begin{abstract}
A revista trata o branco como sinônimo de turista, pois o considera como elite simbólica, ou representante legítimo da espécie humana. Outra hipótese é que a produção do turismo-mercadoria deve ser "limpa", no sentido eugênico, e produzida dentro dos padrões da ideologia étnica do modelo-padrão: o consumidor branco. Como desdobramento, a revista é produzida para um público-alvo majoritariamente composto por pessoas brancas. (Hintze \& Almeida Júnior, 2012, p. 67).
\end{abstract}

Sobre os negros retratados na revista, eles são colocados como trabalhadores do turismo, são aqueles que servem nos bastidores da atividade. (Hintze \& Almeida Júnior, 2012). Ao analisar as imagens em que estes trabalhadores aparecem, há um reforço da ideia de povos "calorosos", em uma romantização das sociedades locais que recebem os turistas. (Hintze \& Almeida Júnior, 2012).

Outra imagem do negro, disposta na Viagem e Turismo é um ser exotizado e sexualizado, em especial quando são retratadas pessoas do continente africano. A imagem dos negros também está relacionada ao carnaval e ao futebol, à cultura e à religiosidade, (Hintze \& Almeida Júnior, 2012), caindo nos padrões que estereotipam os negros. Como afirma Carneiro (2004), “uma das características do racismo é a maneira pela qual ele aprisiona o outro em imagens fixas e estereotipadas, enquanto reserva para os racialmente hegemônicos o privilégio de serem representados em sua diversidade".

Como resultado, os autores concluíram que a comunicação e, portanto, a produção turística no Brasil, no caso do objeto de estudos - a revista Viagem e Turismo, é "consideravelmente influenciada pela ideologia racista".

O que pesquisa de Hintze e Almeida Júnior (2012) mostra, em termos gerais, é que o negro, no turismo, é apontado sempre como trabalhador, e, embora empreendedores negros e afroempreendedores sejam trabalhadores, não são vistos na atividade, não são retratados nela. Neste sentido, o afroempreender em turismo serve para mudar a "visão do negro como mão de obra", como afirmou um entrevistado e ainda para, como mostrou outro entrevistado:

\footnotetext{
Inspirar a construção de novas referências representativas no ambiente de negócios e empresarial para que futuras gerações possam sonhar com suas próprias empresas e seus negócios de alta performance e rentabilidade. Reforça, assim, a multiplicidade e diversidade de lugares sociais que podem e devem ser ocupados por nós além dos lugares de subalternidade que o racismo tenta nos enquadrar.
} 
Como mostra a fala acima, o afroempreendedorismo serve para mostrar que o negro pode e está em diferentes espaços da atividade turística, influenciando os que vêm depois a se verem ali representados.

Outra categoria, criada a partir da fala dos pesquisados, diz respeito à educação de jovens, o que leva à discussão do turismo pedagógico auxiliando na propagação do conhecimento da cultura negra e no combate ao racismo, fomentado pelas propostas elaboradas pelos afroempreendedores.

Matos (2012) esclarece que o turismo pedagógico tem uma relação direta e indireta com o processo ensino-aprendizagem, visto que se configura por meio de atividades didático - pedagógicas que estão incluídas no currículo escolar. A proposta é que se estabeleçam relações com o conteúdo programático dos currículos escolares e que a saída da sala de aula contribua na apropriação do que foi ensinado. Segundo Matos (2012), estas atividades, na pedagogia, denominam-se estudo do meio.

O turismo pedagógico, para Bomfim (2010, p. 126):

é uma prática que procura proporcionar a convivência entre pessoas de culturas diferentes, apresentando situações favoráveis para a prática do aprender a conhecer, a fazer, a conviver e a ser, propiciando uma pedagogia participativa, na qual os alunos serão estimulados a se envolver ativamente.

A perspectiva de turismo pedagógico discutida envolve o ensino da cultura negra de maneira que ocorra o conhecimento, o respeito e a valorização desta, o que pode ser feito a partir de diferentes caminhos que confluem o turismo e a sala de aula. Vale lembrar que existe a Lei $n^{\circ} 10.639$ (2003) (e sua ampliação, na Lei $n^{\circ} 11.645,2008$ ), que institui o ensino da história e cultura afro-brasileira e africana no currículo dos estudantes do país.

É importante que as vivências experienciadas pelos estudantes deem conta da cultura afro em toda sua amplitude, isto é, fugindo de visões simplistas e que colocam os negros como escravos. Sobre o assunto, Bandeira (2018, p. 5), que é técnica em guia de turismo, doutoranda e história e que faz roteiros de turismo pedagógico no estado do Rio de Janeiro, conta um pouco de sua experiência:

Atento os passageiros para as marcas do processo histórico da construção de uma brasilidade embranquecida, que é observado na arquitetura eclética de inspiração europeia, na escassez de monumentos como suportes de memórias ameríndia e negra, bem como na tensão latente (sic) nas relações étnico-raciais no centro da cidade. Embora quisesse estender o turismo histórico para o Vale do Café, não me agradavam os produtos comercializados pelos hotéis-fazenda, em que eram frequentes as visitas teatralizadas reforçando o papel dos afro-brasileiros no lugar do escravizado. Aceitando um discurso que minimizava a barbárie do escravismo em nome do consumo de uma experiência histórica bizarra, o turismo acrítico. [...] 
Observei que, nas agências de turismo, os roteiros às fazendas do Vale do Paraíba eram oferecidos às escolas particulares e aos turistas sem nenhum questionamento sobre a inadequação de uma exposição de itens de tortura na senzala e o completo silêncio sobre expressões culturais de origem popular, como o jongo por exemplo.

Neste sentido, para que o turismo pedagógico alcance seu objetivo e efetivamente ocorra, é indispensável um olhar educativo sobre o assunto, que estimulará uma visão crítica dos estudantes, haja vista que, se esta não for feita " [...] pode provocar teatralização dessa cultura, a exclusão da comunidade e a ratificação de patrimônios escolhidos por interesses oficiais ou econômicos” (Magalhães \& Castelo Branco, 2006, p. 10).

Também neste sentido, Bandeira (2018, p. 13) esclarece que a noção de turismo pedagógico como "dia do passeio" precisa ser superada, não apenas pela melhor integração entre professores e guias, mas também para que se possa abordar "temas sensíveis como a diáspora africana com preparo prévio para lidar com as emoções que surgem da experiência, o que demanda ação dos professores em sala de aula antes da atividade externa".

Finalizando esta categoria, aproveito ainda para abrir outro flanco, que não será aqui desdobrado, mas que precisa ser instigado, a da necessidade de conhecimento, pelos guias de turismo e turismólogos, da história afro brasileira, assim como o debate universitário e a produção científica sobre turismo e relações étnico-raciais. Corroboro Costa (2014, p. 209) quando o autor pontua que as licenciaturas têm em seus currículos:

o estudo da História da África e dos Africanos, a luta dos negros no Brasil, a cultura negra brasileira e o negro na formação da sociedade nacional, resgatando a contribuição do povo negro nas áreas social, econômica e política pertinentes à História do Brasil. Já os profissionais egressos de cursos de bacharelado, como é o caso do Turismo, ainda carecem desta abordagem. Ela deveria ser obrigatória nos currículos, o que facilitaria o seu posicionamento perante uma sociedade diversa e heterogênea. As diretrizes curriculares do curso de Turismo não contemplam as relações étnico-raciais, por conseguinte os egressos destes cursos não discutirão, durante a sua formação acadêmica, temáticas relacionadas às relações étnico-raciais, consequentemente refletindo pouco sobre o assunto.

Neste sentido, para que o profissional de turismo realmente auxilie no combate o racismo e na valorização da cultura afro brasileira, é importante que ele compreenda seu lugar de fala e que tenha conhecimento do assunto, o que não é instigado nos currículos educacionais dos cursos em turismo do Brasil.

Outra categoria criada a partir da fala dos entrevistados diz respeito à adoção de medidas antirracistas nos negócios, o que vai ao encontro das discussões atuais sobre manifestações antirracistas que andam acontecendo no mundo todo.

A cada ocorrência de racismo que ganha a mídia mundial, muitas empresas levantam a hashtag BlackLivesMatter, mudam seus perfis nas redes sociais e afirmam apoiar os 
movimentos negros. A questão é, o que realmente elas têm feito para combater o racismo e lutar pela diversidade em todos os ambientes? De qual modelo de negócios estas empresas fazem parte? O caso George Floyd (segurança negro morto por um policial branco em maio de 2020 em Minneapolis, Estados Unidos) foi o ato mais recente que impactou todo o mundo (ainda que, no Brasil, muitos “Joãos Pedros”, “Ágathas”, "Miguel”, “Amarildos” morram todos os dias) e evidenciou a discussão sobre ativismo social de empresas, chamados de ativismo de marca.

Como afirma Pepper Miller, que é uma estadunidense consultora de diversidade, embora muitas empresas tenham adotado rapidamente a hashtag do movimento em redes sociais, elas não parecem demonstrar o mesmo entusiasmo em seu quadro de diretores visto que, em 2020, apenas quatro das 500 maiores empresas dos Estados Unidos tinham um diretor-executivo negro. Além disso, há também empresas que anunciam doações em dinheiro para causas antirracismo, contudo, outras ações da mesma companhia passam uma mensagem ambígua. (Duarte, 2020).

De acordo com Luana Genot, fundadora do Instituto Identidades do Brasil, é necessário que as empresas olhem quantas pessoas negras possuem em seus espaços, quantas estão de fato em cargos de poder, em cargos de liderança, que tipo de mensagem essas corporações tem enviado ao seu público, quais tipos de projetos essas empresas e organizações têm apoiado ao longo do ano, quantos são liderados por pessoas negras e quantos são ligados à temática racial. Como esclarece Genot, são as respostas a estas perguntas que irão validar o quanto vidas negras importam em cada ambiente corporativo. (Rocha, 2020).

A publicitária Gabriela Rodrigues vai no mesmo sentido e esclarece que os empreendimentos deveriam começar pela autocrítica, analisando seus dados. Depois, é necessário que os vieses da marca sejam estudados, pois "todo mundo tem vieses inconscientes ligados à questão de raça”. Assim, é necessário se questionar como estes influenciam nas atitudes da empresa. É indispensável que seja construído e implementado um plano de ação institucional, com metas e estratégias para resolver os problemas que foram mapeados, com prazos, equipe responsável, verbas. Após estas etapas, em que políticas de contratação, planos de carreira, promoção, salários justos e projetos de responsabilidade social ligados ao campo de atuação da marca são delineados, aí sim a marca tem propriedade para se posicionar. (Rocha, 2020). 
O afroempreendedorismo, ao ser pautado pela viés da raça, contribui, como falaram os pesquisados, na adoção de medidas antirracistas nos modelos de negócios, o que auxilia na redução da desigualdade racial e na afirmação da identidade negra.

Como última categoria, a renda e inclusão do capital de giro para a população afrodescendente foi destacada de maneira veemente pelos pesquisados, sendo intrínseco a proposta do afroempreendedorismo, que envolve, em seus princípios, a produção da e para a cultura negra, de maneira a criar uma rede que faz o capital girar entre os negros do país.

A ideia da geração de renda e capital de giro entre os negros é a ideia, aqui já mencionada, do Black Money, que objetiva fazer com o dinheiro fique as mãos dos pretos e circule entre eles. Ela atua em várias frentes que objetivam a redução da desigualdade social. Por exemplo, para conseguir crédito, uma das maiores dificuldades que os negros enfrentam ao abrirem seus próprios negócios (Paixão, 2014; Pretahub, 2019), já existem bancos, como o Conta Black, o Banco Afro, D'Black Bank, Afrobank, criados a partir de experiências negativas de negros com pedido de créditos em bancos convencionais. Com acesso ao crédito, o afroempreender tem capacidade de iniciar seu negócio, empregar pessoas e vender seus produtos, atuando em diferentes frentes que auxiliam na redução da desigualdade racial, pois, como um dos entrevistados explicou "afroempreendedorismo fomenta a geração de riqueza entre a população negra, a partir da determinação estratégica de construir meios e serviços que atendam às demandas específicas da população".

Outro respondente lembrou ainda que, com seu trabalho, auxilia na "distribuição de renda e maior oferta de oportunidades profissionais para pessoas negras", além de "promover o empoderamento econômico tão necessário" para os negros do país, apontou outro afroempreendedor.

As respostas encontradas vão ao encontro do que Nascimento (2018, p. 3) afirma quando reflete que, embora os produtos criados pelos afroempreendedores não sejam necessariamente exclusivos para uma população preta e parda, há um:

objetivo por trás da prática da maioria destes afroempreendedores: muitos
consideram que o mercado entre pessoas negras, a troca de serviços e produtos que
valorizam etnicidade afro-brasileira e a formação de uma rede de empregabilidade
entre empreendedores negros são formas de ativismo contra o racismo. Certamente,
o prefixo "afro" carrega um valor semântico muito significativo para os
empreendedores negros que compreendem o empreendedorismo como uma
atividade comercial e, também, como um dever social de enfrentamento ao racismo
e valorização das raízes étnico e culturais de matriz africana e afro-brasileira.

Entre tantos argumentos citados pelos afroempreendedores pesquisados, o de geração de renda é o mais imediato na busca pela redução da desigualdade racial no país e o turismo 
auxilia ao fortalecer as narrativas afroreferenciadas e fazer delas um caminho para um outro turismo, um turismo crítico.

\section{CONSIDERAÇÕES FINAIS}

A pesquisa mostrou como pensam 15 afroempreendedores em turismo no Brasil. São principalmente mulheres, com alta escolaridade, que trabalham principalmente com agenciamento e guia, sendo microempreendedores em sua maioria, que sabem o que é Black Money e afirmam dar preferência a outros afroempreendedores quando utilizam serviços ou fazem compras.

Estas pessoas mostraram setes caminhos pelos quais o afroempreender em turismo auxilia em dois problemas que afligem o Brasil, a desigualdade racial e o enfraquecimento da identidade negra. Ambos os problemas são característicos de uma sociedade racista que buscou, por muito tempo, branquear a sua população, que afirmou que o Brasil era um ambiente de democracia racial e que aqui não haveria racismo. É nesta sociedade, que até hoje menospreza a cultura negra, a silencia ou ainda a exotiza, que os afroempreendedores procuram caminhos para contribuir com um país mais igual, e o fazem por setes diferentes meios aqui relatados. São vias próximas uma da outra, mas que trazem, cada uma, sua peculiaridade que contribui com algum ponto em específico.

Por exemplo, embora falar de resgate da memória do povo preto por meio de narrativas turísticas e valorização de narrativas negras e da ancestralidade pareça a mesma coisa, há duas vertentes, que conversam e se apoiam. Enquanto a primeira busca desvelar as memórias subterrâneas, que por tanto tempo foram silenciadas pela sociedade e também pelo turismo, abrindo caminhos para novos lugares de memória, ainda a serem descobertos ou ainda formatados, o segundo se pauta pela valorização de roteiros já estabelecidos, que precisam ser valorizados.

Outro tópico que muito se aproxima destes, mas que também tem sua particularidade em sua significância diz respeito à formação de empreendedores negros que valorizam sua ancestralidade. Os negros foram ensinados a odiar os próprios corpos, a manter seus cabelos "domados", a se comportar de maneira a não chamar atenção e assim cresceram, associando o negro às coisas ruins, maléficas, de modo a não valorizar sua história e dos seus. $\mathrm{O}$ afroempreendedorismo em turismo vem para mostrar aos pretos que é tão importante se orgulhar da própria história a ponto de fazer dela algo que merece ser visto e compartilhado com outras pessoas. 
O afroempreender em turismo também auxilia ao mostrar que o negro é mais do que mão de obra no turismo. Ele pode ser o que ele quiser, turista e também dono do próprio negócio, embora dificilmente seja assim retratado na sociedade. A proposta é que outras pessoas possam ver os empresários negros como exemplos, normalizar que eles também ocupam este espaço.

Outro ponto levantado é a contribuição que o afroempreender em turismo dá ao educar jovens. É por meio da educação, proposta por um turismo pedagógico, que os estudantes podem conhecer a cultura negra e também, muitas vezes, nela se reconhecer. O racismo e a desigualdade racial precisam ser combatidos no dia e a dia e a educação é um caminho importante para tanto. No caso pesquisado, o turismo é um vetor importante. Entretanto, é indispensável que os responsáveis por conduzir a atividade tenham conhecimento do que falam a fim de não disseminar preconceitos e reforçar estereótipos.

No âmbito dos negócios, duas vertentes foram pontuadas, a de que o afroempreender em turismo auxilia ao fazer uso de medidas antirracistas nas empresas, o que deve ser visto como um exemplo a ser seguido por todas as outras e, por fim, contribui ao gerar renda, dar emprego e possibilitar capital de giro entre os seus, formando um ecossistema que se sustenta, se apoia e que tem no turismo pontos de apoio, ainda que esta atividade seja predominante branca, mas que busca, por meio deste afroempreendedores, do afroturismo e dos afroturistas, se abrir e dar valor à diversidade.

\section{REFERÊNCIAS}

Agier, M. (2001). Distúrbios identitários em tempos de globalização. Mana, 7(2), 7-33.

Baldin, N., \& Munhoz, E. M. (2011). Snowball (bola de neve): uma técnica metodológica para pesquisa em educação ambiental. Anais do Congresso Nacional de Educação, Curitiba, PR, Brasil, 10.

Bandeira, F. M. (2018). Roteiro para uma memória afro-brasileira: contribuições para a lei 10639/2003. Anais do Seminário Nacional História e Patrimônio Cultural, Rio de Janeiro, RJ, Brasil, 2.

Barbosa, B. (2018). Número de brasileiros que se declaram pretos cresce no país, diz IBGE. Uol. Recuperado de https://noticias.uol.com.br/cotidiano/ultimas-noticias/2019/05/22/ibgeem-todas-as-regioes-mais-brasileiros-se-declaram-pretos.htm.

Bomfim, M. V. S. (2010). Por uma pedagogia diferenciada: uma reflexão acerca do turismo pedagógico como prática educativa. Turismo Visão e Ação, 12(1), 114-129.

Carneiro, S. (2004). Negros de pele clara. Gelédes. Recuperado de https://www.geledes.org.br/negros-de-pele-clara-por-sueli-carneiro/. 
Carneiro, S. (2009). A miscigenação racial no Brasil. Gelédes. Recuperado de https://www.geledes.org.br/miscigenacao-racial-brasil/.

Castells, M. (2000). O poder da identidade. (2a. ed.). Paz e Terra.

Costa, R. D. (2014). Turismo, educação e ação afirmativa: considerações preliminares sobre formação superior em turismo. [STN]THESIS, 7(2), 205-216.

Dias, G. S. (2020a). O ano do afroturismo no Brasil: novas empresas, novas viagens, fóruns e redes. Guia Negro. Recuperado de http://guianegro.com.br/o-ano-do-afroturismo-no-brasilnovas-empresas-novas-viagens-foruns-e-redes/.

Dias, G. S. (2020b). Rede de Afroturismo apresenta mapeamento do setor. Guia Negro. Recuperado de https://guianegro.com.br/rede-de-afroturismo-apresenta-mapeamento-dosetor/.

Domingos, A. B., Pimentel, J. M. V., \& Queiroz, W. N. (2018). Diáspora. black transformando a segregação em segmentação no turismo. Anais do Fórum Internacional de Turismo do Iguassu, Foz do Iguaçu, PR, Brasil, 12.

Duarte, F. (2020). "Ativismo de marca" e protestos contra o racismo: como saber se as empresas praticam o que dizem. BBC News. Recuperado de https://www.bbc.com/portuguese/geral-53017558.

Equipe Lupa. (2018). Pnad Contínua: cinco verdades sobre a renda dos brasileiros em 2017. Piauí. Recuperado de https://piaui.folha.uol.com.br/lupa/2018/04/13/cinco-verdades-rendabrasil/.

Fazito, M. (2015). Modernização turística: o papel do turismo nos discursos dominantes de desenvolvimento. In Figueiredo, S.L., Azevedo, F. F., \& Nóbrega, W. R. M. (Orgs). Perspectivas contemporâneas de análise em turismo. NAEA. Recuperado de https://livroaberto.ufpa.br/jspui/bitstream/prefix/16/1/Livro_PerspectivasContemporaneasAna lise.pdf.

Hintze, H., \& Almeida Júnior, A. R. (2012). Estudos críticos em turismo: a comunicação turística e o mito da democracia racial no Brasil. Turismo e Desenvolvimento, 17/18, 57-72.

Instituto Brasileiro de Geografia e Estatística - IBGE. (2018). IBGE mostra as cores da desigualdade. 2018. Recuperado de https://agenciadenoticias.ibge.gov.br/agencianoticias/2012-agencia-de-noticias/noticias/21206-ibge-mostra-as-cores-dadesigualdade.

Instituto Brasileiro de Geografia e Estatística - IBGE. (2019). Desigualdades sociais por cor ou raça no Brasil. Estudos e pesquisas: informação demográfica e socioeconômica, 41. Recuperado de https://biblioteca.ibge.gov.br/visualizacao/livros/liv101681_informativo.pdf.

Lei $n^{\circ}$ 10.639, de 9 de janeiro de 2003. (2003). Altera a Lei no 9.394, de 20 de dezembro de 1996, que estabelece as diretrizes e bases da educação nacional, para incluir no currículo oficial da Rede de Ensino a obrigatoriedade da temática "História e Cultura Afro-Brasileira", e dá outras providências. Brasília, DF. Recuperado de http://www.planalto.gov.br/ccivil_03/leis/2003/110.639.htm\#: :text=L10639\&text=LEI\%20N o\%2010.639\%2C\%20DE\%209\%20DE\%20JANEIRO\%20DE\%202003.\&text=Altera\%20a\% 20Lei\%20no,\%22\%2C\%20e\%20d\%C3\%A1\%20outras\%20provid\%C3\%AAncias. 
Lei $n^{o} 11.645$, de 10 março de 2008. (2008). Altera a Lei no 9.394, de 20 de dezembro de 1996, modificada pela Lei no 10.639, de 9 de janeiro de 2003, que estabelece as diretrizes e bases da educação nacional, para incluir no currículo oficial da rede de ensino a obrigatoriedade da temática "História e Cultura Afro-Brasileira e Indígena". Brasília, DF. Recuperado de http://www.planalto.gov.br/ccivil_03/_ato2007-2010/2008/lei/111645.htm

Magalhães, L. H., \& Castelo Branco, P. M. (2006). Patrimônio, memória e turismo: um exercício do olhar. Perspectiva Contemporânea, 1 (1), 1-13.

Matos, F. de C. (2012). Turismo pedagógico: o estudo do meio como ferramenta fomentadora do currículo escolar. Anais do Seminário de Pesquisa Em Turismo do Mercosul, Caxias do Sul, RS, Brasil, 7.

Moherdaui, B, Datt, F., \& Moura, M. (2019). Ele criou um serviço de hospedagem que valoriza a cultura negra. PEGN. Recuperado de https://revistapegn.globo.com/Banco-deideias/Diversao-e-turismo/noticia/2019/07/ele-criou-um-servico-de-hospedagem-quevaloriza-cultura-negra.html.

Munanga, K. (1999). Rediscutindo a mestiçagem no Brasil. Vozes.

Nascimento, E. Q. (2017). Empreendedorismo: efeito refúgio ou oportunidade? Uma análise do empreendedorismo como estratégia de inclusão socioeconômica para a população negra. Trabalho de conclusão de curso, Universidade Federal do Espírito Santo, Vitória, Espírito Santo, Brasil.

Nascimento, E. Q. (2018). Afroempreendedorismo como estratégia de inclusão socioeconômica. Anais do Seminário de Ciências Sociais - PGCS UFES, Vitória, Espírito Santo, Brasil.

Nogueira, J. C. (Org.). (2013). Desenvolvimento e empreendedorismo afrobrasileiro: desafios históricos e perspectivas para o século 21. Atilènde.

Nora, P. (1993). Entre memória e história: a problemática dos lugares. Projeto História, 10, 7 28.

Oliveira, J. S., Pereira, J. A., \& Souza, M. C. D. (2013). Empreendedorismo, cultura e diversidade: a participação dos empreendedores negros nas atividades empreendedoras no Brasil no período de 1990 a 2008. Contextus: Revista Contemporânea de Economia e Gestão, 11(2), 7-30.

Oliveira, T. S. (2019). Redes sociais na internet e a economia étnica: um estudo sobre o afroempreendedorismo no Brasil. Dissertação de Mestrado, Universidade Federal do ABC, Santo André, São Paulo, Brasil.

Oliveira. N. A. (2010). Xavante, Pioneiros e Gaúchos: identidade e sociabilidade em Nova Xavantina/MT. Dissertação de Mestrado, Universidade do Vale do Rio dos Sinos, São Leopoldo, Rio Grande do Sul, Brasil.

Paixão, M. J. (2014). Empreendedores negros ainda têm dificuldades em conseguir crédito. https://empreendedor.com.br/noticia/empreendedores-negros-ainda-tem-dificuldade-emconseguir-credito/.

Pollak, M. (1989). Memória, esquecimento, silêncio. Estudos históricos, 2(3), 3-15. 
Pretahub. (2019). Empreendedorismo negro no Brasil 2019. https://gife.org.br/estudo-dapretahub-mapeia-tres-perfis-de-empreendedores-negros-no-brasil/.

Rocha, C. (2020). O que uma empresa pode fazer contra o racismo além de post na internet. Nexo. https://www.nexojornal.com.br/expresso/2020/06/03/O-que-uma-empresa-pode-fazercontra-o-racismo-al\%C3\%A9m-de-post-na-internet.

Rossi, M. (2015). Mais brasileiros se declaram negros e pardos e reduze números de brancos. El País. https://brasil.elpais.com/brasil/2015/11/13/politica/1447439643_374264.html.

Schlüter, R. G. (2003). Metodologia da pesquisa em turismo e hotelaria. Aleph.

Silva, F. A. (2008). A frente negra pernambucana e sua proposta de educação para a população negra na ótica de um de seus fundadores: José Vicente Rodrigues Lima - década de 1930. Tese de Doutorado, Universidade Federal do Ceará, Fortaleza, Ceará, Brasil.

Silva, G. (2019). Black Money: o futuro dos afroempreendedores no Brasil. https://inteligencia.rockcontent.com/black-money/.

Souza, J. (2012, fevereiro). Afrodescendência: identidade desvelada na memória. Anais do Simpósio Nacional Discurso, Identidade e Sociedade, Campinas, SP, Brasil.

OLIVEIRA, N. A. (2021). Afroempreendedorismo no turismo, desigualdade racial e fortalecimento da identidade negra. Revista de Turismo Contemporâneo, 9(1), 42-63. https://doi.org/10.21680/2357-8211.2021v9n1ID22322 